\section{Waist-To-Height Ratio, Lean Mass and Fat Mass in Preschool Children}

Thais Costa Machado ${ }^{1}$ Viviane G. Nascimento ${ }^{2}$, Ciro João Bertoli ${ }^{3}$, Luiz Carlos Abreu 4,5 , Claudio Leone ${ }^{6}$

1 Department of Maternal and Child Health, School of Public Health (Faculdade de Saúde Pública- FSP), University of São Paulo (Universidade de São Paulo- USP), São Paulo, SP, Brazil.

Introduction: Abdominal fat and the proportion of lean body mass have both been independently considered as risk factors leading to insulin resistance and to an increased risk of developing chronic diseases later in life.

Objective: To analyse the relationship between the waist-to-height ratio (WHtR) and other body composition indicators in children aged 2-6 years at public childcare centres.

Methods: This study consisted of a random, probabilistic cluster sampling of 9 of the 59 existing childcare centres (Taubaté-SP, Brazil), resulting in the evaluation of 950 preschool children. The body mass index z-score (zBMI) and internationally accepted cut-off points were used to evaluate their nutritional status. The z-score for the arm muscle area (ZAMA) and arm fat area (ZAFA) and the WHtR were used to evaluate their body composition. Analyses were performed using the parameters of central tendency, dispersion, proportions and correlations, adopting a significance level of $5 \%$.

Results: The data indicated a direct correlation between the WHtR and $z$ BMI $\left(r_{p}=0.78\right)$, zAMA $\left(r_{p}=0.52\right)$, zAFA $\left(r_{p}=0.66\right)$ and the percentage of AFA $\left(r_{p}=0.54\right)$, with $p<0.0001$. There was an inverse correlation between the WHtR and the percentage of AMA $\left(r_{P}=-0.54\right)$, with $p<0.0001$.

Conclusion: In preschool children, as the WHtR increases, the amounts of both lean body mass and body fat mass also increase. However, an increase in the waist circumference is accompanied by a disproportionately greater increase in fat mass compared to lean mass, which could indicate an additional risk factor for future chronic diseases.

2 Post-Doctoral Fellow, Department of Maternal and Child Health, FSP/ USP. Lecturer at Paulista University (Universidade Paulista- UNIP), São Paulo, SP, Brazil.

3 Lecturer, Department of Medicine, University of Taubaté (Universidade de Taubaté - UNITAU), Taubaté, SP, Brazil.

4 Researh in Program in Molecular and Integrative Physiological Sciences (MIPS). Department of Environmental Health, Harvard T.H. Chan School of Public Health.

5 Lecturer and Head, Department of Public Health, ABC School of Medicine, Santo André, SP, Brazil.

6 Full Professor, Department of Maternal and Child Health, FSP/USP, São Paulo, SP, Brazil.

\section{Contact information:}

\section{Claudio Leone.}

Address: Av. Dr. Arnaldo, 715. CEP: 01246-904. São Paulo-SP. Brazil. Department of Maternal and Child HealthFSP-USP.

Tel: + 551130617974

झleone.claudio@usp.br

Keywords

Body Composition; Preschool

Children; Obesity; Waist

Circumference. 


\section{Introduction}

The importance of using the waist circumference to estimate visceral fat has been underscored, even if indirectly, primarily in screening for the risk of developing chronic diseases, which have been associated with an increased accumulation of abdominal fat [1, $14,17]$. The mechanism by which the accumulation of central fat, specifically visceral fat, leads to insulin resistance likely stems from an increase in lipolysis and the release of free fatty acids. Moreover, insulin resistance is associated with the appearance of several risk factors for diseases such as glucose intolerance, dyslipidaemia, vascular injury, hypertension and other cardiovascular disorders, which are the major components of metabolic syndrome [6, 27].

A meta-analysis study found evidence supporting the superiority of measuring central obesity, especially using the waist-to-height ratio (WHtR), compared to Body Mass Index (BMI) in detecting cardiovascular risks in adult men and women [13]. However, in children and especially in pre-school age children, there is no consensus on this score because some authors have found no difference between the use of BMI and the use of waist circumference measurements in predicting cardiometabolic risks [5, 8, 12], whereas other authors have reported differences between them, considering waist circumference measurements to be a better predictor of this type of risk $[15,18,24]$.

In addition to visceral fat, muscle mass has also been associated with the body's ability to regulate the glucose metabolism. Because muscle is an important site for glucose uptake, metabolism and storage, reduced body muscle mass can be considered another factor capable of leading to insulin resistance, thereby increasing the risk of developing chronic diseases later in life [22, 25, 32].

The majority of these studies have independently evaluated the risk of developing chronic diseases at different stages of life, associating these risks with fat accumulation in the central region or with a reduction in lean body mass. Few studies have evaluated the simultaneous manifestation or the correlation between these two risk factors [10, 32]. Across-sectional study conducted in Finnish adults observed a positive correlation between waist circumference and both lean and fat body mass [32].

IBÁÑEZ et al. [10] published the only study among preschool age children and reported that central fat gain was accompanied by a greater gain in body fat mass than in muscle mass, but only in children who were small for their gestational age at birth.

Considering that both excess fat and decreased lean body mass in children may represent risk factors for medium and long-term health, the evaluation of body composition during childhood has become extremely important. The early detection of changes in these factors may contribute to the development of more effective measures to prevent obesity and its potential complications. Thus, given the importance of this topic and the still outstanding issues, this research was conducted to study the relationship between the $\mathrm{WHtR}$, lean mass and body fat mass in children aged 2-6 years.

\section{Methods}

This work was a cross-sectional study where the study population consisted of children between the ages of 2 and 6 years who were enrolled and attending municipal childcare centres in Taubaté (São Paulo state - SP) during the second half of 2008 and the first half of 2009. The sampling was probabilistic and random, clustered by the childcare centres themselves, based on the list of the 59 municipallyowned childcare centres that existed at that time.

The sample size required was estimated to be 112 overweight children, with a Pearson correlation coefficient of 0.30 between the WHtR and lean body mass, for a statistical power of $90 \%$ and a significance level of $5 \%$. Given that the prevalence of overweight preschool children in Taubaté was approximately $15 \%$, the final sample required was estimated to be 747 children. The sample size cal- 
culations were performed using the software MedCalc version 12.1.4.0.

To compensate for possible sampling losses, the sampling group was expanded by $20 \%$, requiring a final sampling of 896 children. The first 9 childcare centres randomly selected among the 59 existing centres were more than sufficient to achieve the necessary sample size.

All children between 2 and 6 years of age who were enrolled and attending the childcare centres and present on the days scheduled for taking the anthropometric measurements were included in the study. Children with chronic or growth disorders and children whose parents or guardians did not authorise participation were not included in the study.

The nine childcare centres resulted in a total of 954 children who underwent the weight, height, arm circumference (AC), waist circumference (WC) and triceps skinfold thickness (TST) evaluations. After the process of analysing and evaluating the data consistency, four children whose values were inconsistent were excluded, resulting in a final sample of 950 children.

The average age of the sample was $4.8 \pm 0.96$ years (standard deviation -SD), with a minimum age of 2.0 years and a maximum age of 6.8 years. Boys accounted for $54.7 \%$ of the children tested. The socioeconomic status of these preschool children was as follows: over half of the children lived in households with 4 or 5 people (52.5\%) and without other children younger than 5 years of age (66.2\%). In addition, $45.1 \%$ of mothers and $35.8 \%$ of fathers had at least nine full years of education.

Anthropometric measurements were taken at the childcare centre it self on scheduled days. Nutritionists and students in their final years of Medical School at the University of Taubaté (Universidade de Taubaté) who had been previously trained, standardised and qualified to complete the instruments collected the weights and heights of the children. The data for body composition, circumference and skinfolds were collected only by previously trained and standardised nutritionists. All body measurements were collected according to the technical standards recommended by the World Health Organisation $[20,28,29]$.

The weights were measured using a Seca ${ }^{\circledR}$ portable digital scale with 150-kg capacity and 100-g precision (Seca ${ }^{\circledR 803), ~ a n d ~ t h e ~ h e i g h t s ~ w e r e ~ m e a s u-~}$ red using a WISO ${ }^{\circledR}$ portable stadiometer that was graduated in centimetres and millimetres and attached to the wall.

The arm circumference (AC) was measured using a $0.5-\mathrm{cm}$-width inextensible tape measure without compressing the midpoint of the non-dominant arm between the acromion and the olecranon and with the child in a standing position with his/her arms relaxed alongside the body.

The WC was measured using an inextensible tape measure at the midpoint between the last rib and the iliac crest, aligned on a horizontal plane, parallel to the floor, with the child standing, his/her arms relaxed alongside the body, feet together and abdomen relaxed. Measurements were taken upon expiration [17, 29].

The TST was measured at the midpoint of the dorsal surface of the non-dominant arm using a properly calibrated Lange ${ }^{\circledR}$ skinfold calliper at a constant pressure. The skinfold measurements were taken in duplicate, and if there was a discrepancy, the procedure was repeated. The mean of the recorded values was then calculated.

The arm muscle area (AMA) and arm fat area (AFA) were used as indirect indicators of lean and fat body mass. They were estimated using the formulas proposed by BAKER et al. [2] to calculate the total area of the arm (ATA) based on the AC and the formulas proposed by JellifFe and Jelliffe [11] to calculate the AMA and AFA from the AC and TST. Although there are different formulas for calculating body composition, in the case of indirect methods, the methods proposed by BAKER et al. [2] and JelLIFFE and JeluFfFE [11] have been and are currently being used in studies involving children $[4,7,9]$. 
As a reference to characterise the nutritional status of the preschool children according to the BMI z-score (zBMI), the 2006 WHO growth curves [30] were used for children up to 5 years of age, and the 2007 WHO growth curves [31] were used for children 5 years of age and older. The reference standards reported by Frisancho [9] were adopted to calculate the AMA, AFA and WC z-scores.

The percentage of AFA (\%AFA) and AMA (\%AMA) in relation to the ATA and the WHtR were also calculated. The WC $(\mathrm{cm})$ to height $(\mathrm{cm})$ ratio has been used, even in children, to control for the influence of the gender and age variables on the WC $[1,14,26]$.

BMI z-scores based on the cut-off points proposed by the Ministry of Health (Ministério da Saúde-MS) and the WHO were used to classify the children's nutritional status [16, 21]. For some analyses, the overweight preschool children were clustered, combining overweight and obese children, using a BMI cut-off of $\geq+2$ z-score. There were 95 children in this group. Moreover, some correlations were calculated exclusively with the group of obese children, using a BMI cut-off of $\geq+3$ z-score, for a total of 42 children.

Data analysis was performed using the applications MedCalc 12.1.4.0 and SPSS 15.0, and the frequencies, proportions, means and standard deviations (SD) and the Pearson correlation coefficients $\left(r_{p}\right)$ were calculated. The alpha level of significance was set at 5\%, and 95\% confidence intervals (CI) were also calculated.

This study was approved by the Committee for Ethics in Research of the College of Public Health, University of São Paulo (Universidade de São Paulo), COEP letter No. 361/09 and by the Research Ethics Committee of the University of Taubaté, CEP/UNITAU No. 0002/05.

\section{Results}

Overall, the children showed an appropriate growth in stature, and their average was not significantly different from WHO reference values for the median height for age z-score (zH/A), i.e., zH/A $=-0.05$ (95\% Cl $=-0.11$ to 0.02 ) with a prevalence of short stature $(\mathrm{zH} / \mathrm{A}<-2)$ of $2.3 \%(95 \% \mathrm{Cl}=1.4$ to 3.5$)$, which is very close to the expected reference values.

The mean BMI z-score of the preschool children was 0.43 (95\% Cl: 0.35 to 0.51$)$ with a SD of 1.22 . For AFA, the mean z-score was 0.60 (95\% Cl: 0.51 to 0.69 ) with a SD of 1.41 , and for AMA, the zscore was $-0.14(95 \% \mathrm{Cl}:-0.21$ to -0.08$)$ with a SD of 1.04 .

The mean WC z-score of the preschool children was 0.61 (95\% Cl: 0.54 to 0.68) with a SD of 1.09 .

The mean WHtR of the preschool children was 0.50 (95\% Cl: 0.497 to 0.502$)$ with a SD of 0.042 .

There was a high correlation, $r_{p}=0.804(p$ $<0.0001$ ), between the WCz-score and WHtR in absolute values in the preschool children analysed.

As evident from Table 1, more than one quarter of the children had a high BMI, and there was a difference in the nutritional status between genders, with a higher prevalence of overweight girls ( $p=0.0009$ ).

Table 1 also shows that there was no malnutrition evident among the children.

An analysis by age group showed no differences in the prevalence of changes in nutritional status.

There was also a direct and very high correlation between the WHtR and the BMI z-score for the preschool age children, with a Pearson correlation coefficient $\left(r_{p}\right)$ of 0.78 , which is statistically significant $(p<0.0001)$.

This correlation remained high, direct and significant even when only the overweight preschool children $\left(r_{p}=0.65, p<0.0001\right)$ or the group of specifically obese children $\left(r_{p}=0.57, p<0.0001\right)$ were analysed.

There was a positive correlation between the WHtR and the AMA z-score $\left(r_{p}=0.52, p<0.0001\right)$, i.e., the higher the $\mathrm{WHtR}$, the greater the $\mathrm{z}$-score AMA in preschool children (Figure 1). However, in analysing the correlation between $\mathrm{WHtR}$ and the percentage of AMA (\%AMA), there was a negative 
Table 1. Prevalence of underweight, risk of overweight, overweight and obesity among preschool children according to gender. Taubate-SP, 2008-2009.

\begin{tabular}{|c|c|c|c|c|c|c|}
\hline \multirow{2}{*}{ Gender } & Under weight & Normal weight & Risk of Overweight & Overweight* & Obesity & Total \\
\hline & $n(\%)$ & $n(\%)$ & $\mathrm{n}(\%)$ & $n(\%)$ & $n(\%)$ & $n(\%)$ \\
\hline M & $\begin{array}{l}5(1.0) \\
(71.4)\end{array}$ & $\begin{array}{c}384(73.8) \\
(55.5)\end{array}$ & $\begin{array}{c}87(16.7) \\
(55.8)\end{array}$ & $\begin{array}{c}17(3.3) \\
(32.1)\end{array}$ & $\begin{array}{c}27(5.2) \\
(64.3)\end{array}$ & $\begin{array}{c}520(100.0) \\
(54.7)\end{array}$ \\
\hline $\mathrm{F}$ & $\begin{array}{l}2(0.5) \\
(28.6)\end{array}$ & $\begin{array}{c}308(71.6) \\
(44.5)\end{array}$ & $\begin{array}{c}69(16.0) \\
(44.2)\end{array}$ & $\begin{array}{c}36(8.4) \\
(67.9)\end{array}$ & $\begin{array}{c}15(3.5) \\
(35.7)\end{array}$ & $\begin{array}{c}430(100.0) \\
(45.3)\end{array}$ \\
\hline \multirow[t]{2}{*}{ Total } & $\begin{array}{l}7(0.7) \\
(100.0)\end{array}$ & $\begin{array}{c}692(72.9) \\
(100.0)\end{array}$ & $\begin{array}{c}156(16.4) \\
(100.0)\end{array}$ & $\begin{array}{l}53(5.6) \\
(100.0)\end{array}$ & $\begin{array}{l}42(4.4) \\
(100.0)\end{array}$ & $\begin{array}{c}950(100.0) \\
(100.0)\end{array}$ \\
\hline & \multicolumn{4}{|c|}{$\chi^{2}=12.834 ; g l=3 ; p=0.005$} & \multicolumn{2}{|c|}{$\mathrm{M} \times \mathrm{F}$ overweight $=0.0009$} \\
\hline
\end{tabular}

Figure 1: Relationship between the WHtR and the z-score for arm muscle area (ZAMA) in preschool children. Taubaté-SP, 20082009.

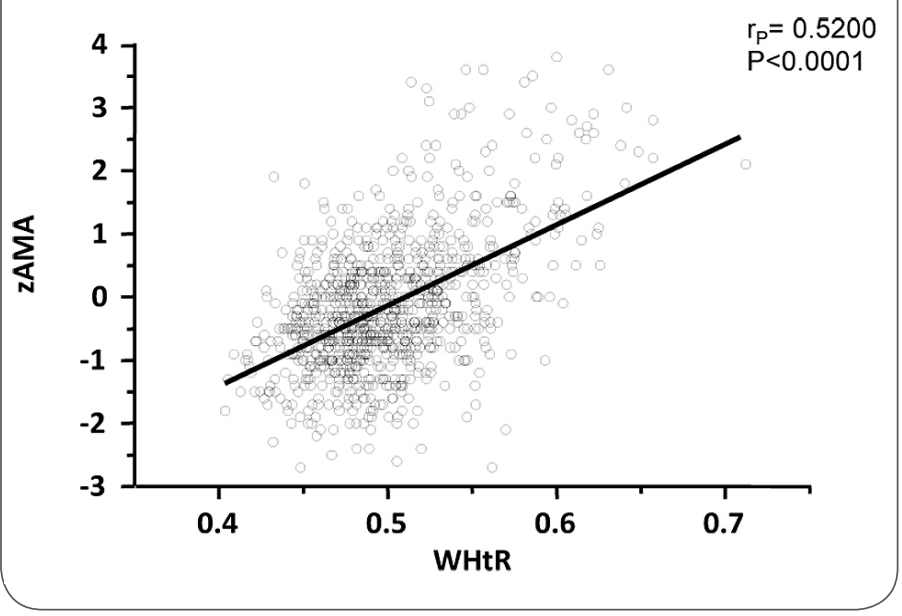

Figure 2: Relationship between the $\mathrm{WHtR}$ and the percentage of arm muscle area (\%AMA) in preschool children. TaubatéSP, 2008-2009.

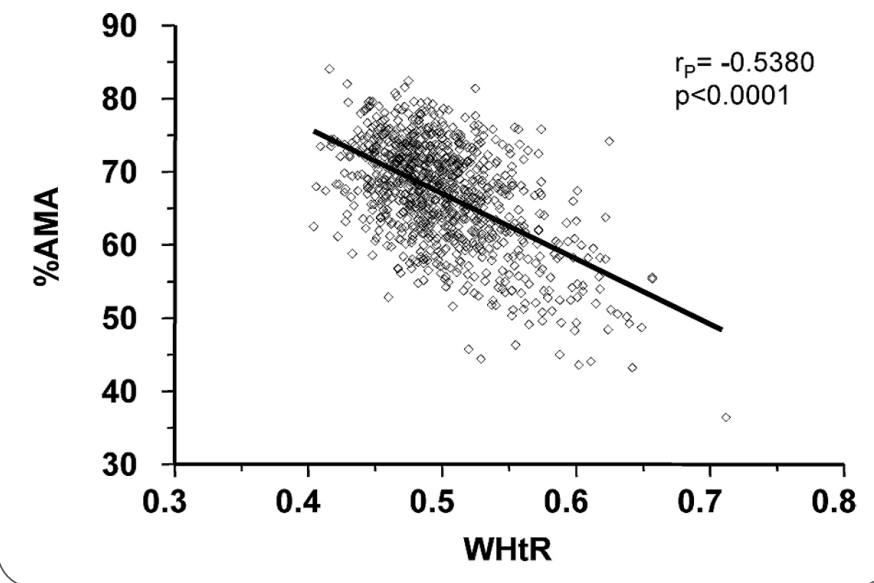

correlation, indicating that as the WHtR increases, the \%AMA decreases in preschool children $\left(r_{p}=\right.$ -0.54, $p<0.0001$ ) (Figure 2).

This correlation between the WHtR and \%AMA was still negative and significant even when only the obese group was analysed $\left(r_{p}=-0.50, p=0.0008\right)$. Regardless of the choice of indicator (ZAFA or $\% A F A)$, as the WHtR increased, there was also an increase in both the $z$-score for AFA $\left(r_{p}=0.66, p\right.$ $<0.0001)$ and the percentage $\left(r_{p}=0.54, p<0.0001\right)$ of this area on the arms of preschool children (Figures 3 and 4).

There was also a positive and significant correlation between the WHtR and \%AFA upon analysing only the group of obese children $\left(r_{p}=0.51, p=\right.$ 0.0006).

Figure 3: Relationship between the $\mathrm{WH} t \mathrm{R}$ and the z-score for arm fat area (ZAFA) in preschool children. Taubaté-SP, 2008-2009.

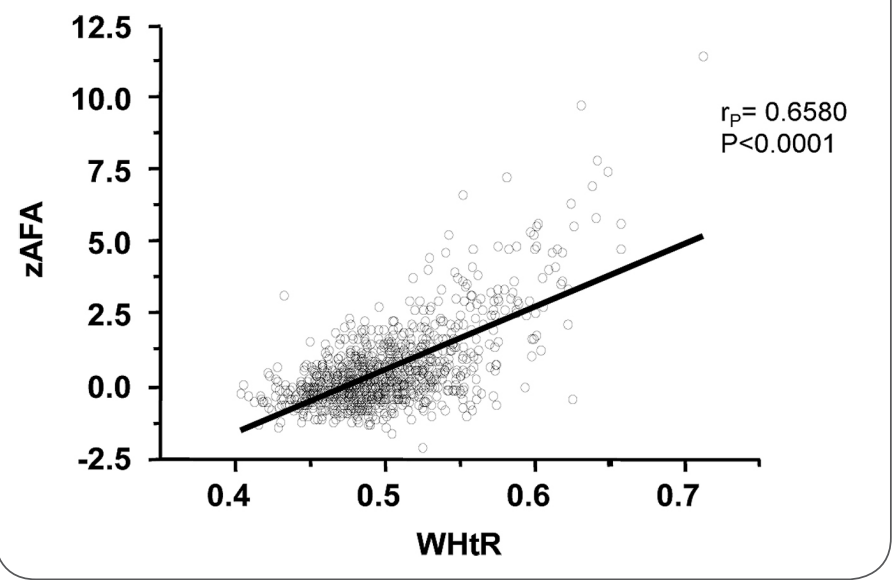


Figure 4: Relationship between the WHtR and the percentage of arm fat area (\%AFA) in preschool children. Taubaté-SP, 20082009

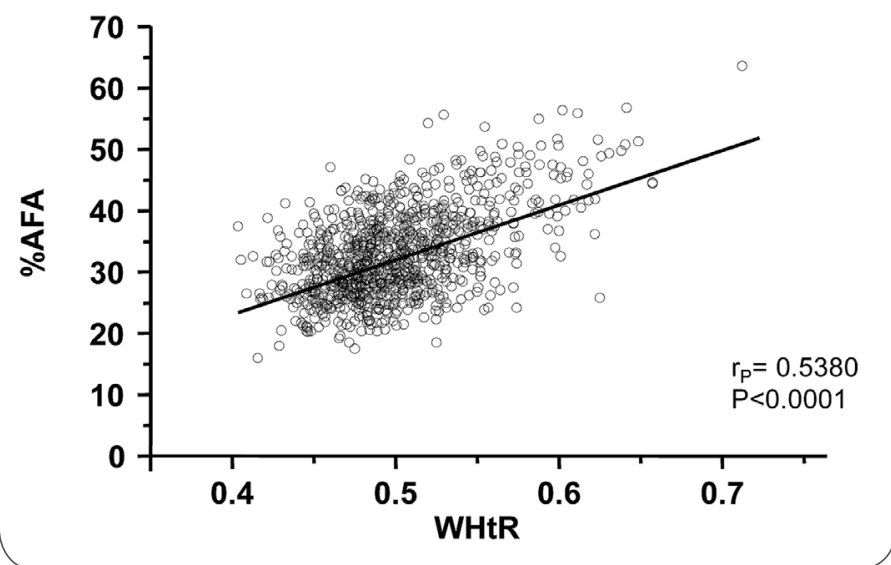

\section{Discussion}

The correlations observed between the WHtR and the zAMA and the \%AMA, as well as between the WHtR and the zAFA and the \%AFA, suggest that as the WHtR increases, the child tends to have a higher quantity, in absolute values, of both muscle mass and body fat mass. However, it is important to note that this trend does not imply that the children had an excess of muscle mass, because whereas the average ZAFA was higher overall than the reference values $(+0.60)$, indicating an increased AFA, the average zAMA was lower $(-0.14$, 95\% $\mathrm{Cl}=-0.21$ to -0.08$)$, indicating that there was less muscle mass.

This difference in z-scores for AFA and AMA, combined with the different correlations observed between the WHtR and the percentages of muscle area and fat area, suggests that even in preschool age children, an increase in the WHtR is accompanied by an increase in fat mass that is disproportionately greater than the increase in lean muscle mass.

Notably, comparing the WC z-score and the WHtR in absolute values showed an almost perfect correlation, indicating that the WHtR can be used as a valid indicator of the tendency for pre-school age children to accumulate fat in the central body region based on their age and gender.

Overall, the WHtR also showed a strong correlation with the BMI of the preschool children, as well as with the overweight or obese children alone. These results also indicate that the WHtR can be used in screening overweight preschool children.

The use of the WHtR in characterising nutritional status may be more practical in routine care than the BMI or WC z-scores or percentiles, as it does not require specific age range and gender tables to diagnose the nutritional risk of the child [26].

Although it may be a possible marker of cardiometabolic risk in preschool age children, the importance of the WHtR is enhanced by its inverse correlation with the percentage (\%) of lean arm area, regardless of the absolute value of this measurement.

This relationship may have a possible explanation in the body's strategic planning, as suggested by RALT [23], that there is a "rivalry" between muscle build-up and height growth during childhood. Thus, in cases of more extreme growth in preschool children, as usually occurs with obese children, the body tends to accumulate more calories as fat mass and proportionately less as muscle mass.

Consistent with the results observed in this study, YLIHÄRSILÄ et al. [32] also reported positive correlations between WC and lean mass and body fat, as well as with the percentage of body fat mass in adults. However, these authors did not examine the correlation between WC and the percentage of lean mass. Boeke et al. [3] evaluated the correlations between different body fat indicators in school age children and also observed a positive correlation between the WHtR and the percentage of body fat estimated using bioelectrical impedance or using dual-energy X-ray absorption (DXA). However, these authors did not evaluate the relationship between WC and lean body mass.

The only study identified that has evaluated the evolution of central fat, lean mass gain and body fat was IBÁÑEZ et al. [10]. These authors reported that between 2 and 4 years of age, there was an 
increase in the gain of abdominal and body fat and a decrease in the gain of lean mass in children who were small for their gestational age at birth, but they did not observe the same trend in children whose birth weights had been appropriate for their gestational age.

In contrast to IBÁÑEZ et al. [10], this study showed that proportionally smaller gains in lean mass may occur among preschool children regardless of their intrauterine growth.

According to MokHA et al. [17], an increased WHtR in children, even in preschool age children, can detect cardiometabolic changes, including among children with normal weights.

Furthermore, health care is conventionally considered the diagnosis, treatment, and prevention of diseases, accidents, and other physical and/or mental disabilities $[33,34]$. As for lean body mass, MuRPHy et al. [19] reported a negative correlation between lean body mass and triglycerides after adjusting for body fat mass in preschool age children.

It was evident in this study that as the WHtR increased, the percentage of lean mass became lower and the body fat mass became much higher in preschool children.

These findings may indicate that children with more fat around their abdominal region and who were heavier at preschool age have a higher risk of developing chronic diseases, given the strong positive correlation observed between WC and BMI.

Thus, considering the relationship between lean body mass and metabolic changes in the body already described in the literature and the results of this study, the evaluation of lean mass is gaining even more obvious importance in routine care in paediatric populations, especially in children who already present with an accumulation of fat in the abdominal region, as also evaluated using the $\mathrm{WHtR}$ in routine care.

\section{Author contributions}

Thais Costa Machado - Study design, data collection, statistical analysis and manuscript preparation;
Viviane G. Nascimento - Study design, analysis of results and final manuscript preparation; Ciro João Bertoli and Luiz Carlos Abreu - Study design, analysis of results and final manuscript preparation; Claudio Leone - Study design, statistical and results analysis, and final manuscript preparation.

\section{Conflicts of interest declaration}

Nothing to declare

\section{Acknowledgement}

This research was supported by the doctoral traning grant from the Brazilian Federal Agency for the Support and Evaluation of Graduate Education (Coordenação de Aperfeiçoamento de Pessoal de Nível Superior- CAPES) and The São Paulo Research Foundation, FAPESP, process 2015/26641-8

\section{References}

1. Ashwell M, Hsieh SD. Six reasons why the waist-to-height ratio is a rapid and effective global indicator for health risks of obesity and how its use could simplify the international public health message on obesity. Int J Food Sciences Nutr. 2005; 56: 303-7.

2. BAKer PT, Hunt EE, Sen T. The growth and interrelations of skinfolds and brachial tissues in man. Am J Phys Anthropol. 1958; 16: 39-58.

3. Boeke CE, Oken E, Kleinman KP, Rifas-Shiman SL, Taveras EM, Gillman MW. Correlations among adiposity measures in schoolaged children. BMC Pediatr. 2013; 13(1): 99.

4. Cândido APC, Freitas SN, Machado-Coelho GLL. Anthropometric measurements and obesity diagnosis in schoolchildren. Acta Pædiatrica. 2011; 100: e120-e4.

5. Chen $\mathrm{B}$, Li H. Waist circumference as an indicator of high blood pressure in preschool obese children. Asia Pac J Clin Nutr. 2011; 20: 557-62.

6. Chiarelli F, Marcovecchio ML. Insulin resistance and obesity in childhood. Eur J Endocrinol. 2008; 159: S67-S74.

7. Chowdhury SD, Ghosh T. The upper arm muscle and fat area of Santal children: an evaluation of nutritional status. Acta Pædiatrica. 2009; 98: 103-6.

8. Freedman DS, Kahn HS, Mei Z, Grummer-Strawn Dietz WH, LM, Srinivasan SR, Berenson GS. Relation of body mass index and waist-to-height ratio to cardiovascular disease risk factors in children and adolescents: the Bogalusa Heart Study. Am J Clin Nutr. 2007; 86: 33-40.

9. Frisancho AR. Anthropometric standards: an interactive nutritional reference of body size and body composition for children and adults. Michigan: The University of Michigan Press, 2008. 
10. IBÁÑEZ L, Ong K, Dunger DB, de Zegher F: Early development of adiposity and insulin resistance after catch-up weight gain in small-for-gestational-age children. J Clin Endocrinol Metab. 2006; 91: 2153-8. Epub 2006 Mar 14.

11. Jelliffe EFP, Jelliffe DB. The arm circumference as a public health index of protein-calorie malnutrition of early childhood. J Trop Pediatr. 1969; 15: 179-88.

12. Kuba VM, Leone C, Damiani D. Is waist-to-height ratio a useful indicator of cardio-metabolic risk in 6-10-year-old children? BMC Pediatrics 2013; 13: 91.

13. Lee CMY, Huxley RR, Wildman RP, Woodward M. Indices of abdominal obesity are better discriminators of cardiovascular risk factors than BMI: a meta-analysis. J Clin Epidemiol. 2008; 61: 646-53.

14. Maffeis C, Banzato C, Talamini G, Obesity Study Group of the Italian Society of Pediatric Endocrinology and Diabetology. Waist-to-Height Ratio, a useful index to identify high metabolic risk in overweight children. J Pediatr. 2008; 152: 207-13.

15. McCarthy HD, Ashwell M. A study of central fatness using waist-to-height ratios in UK children and adolescents over two decades supports the simple message - 'keep your waist circumference to less than half your height'. Int J Obes Relat Metab Disord. 2006; 30: 988-92.

16. Ministério da Saúde. Departamento de atenção básica. Sistema de Vigilância Alimentar e Nutricional. [Ministry of Health. Department of Primary Care. Food and Nutrition Surveillance System]. 2009. Available at: http://nutricao.saude.gov.brll sisvan.php?conteudo=curvas_cresc_oms [2010 Jan 20]

17. Мокна JS, Srinivasan SR, DasMahapatra P, Fernandez C, Chen W, $\mathrm{Xu}$ J, Berenson GS. Utility of waist-to-height ratio in assessing the status of central obesity and related cardiometabolic risk profile among normal weight and overweight/obese children: The Bogalusa Heart Study. BMC Pediatrics. 2010; 10: 73.

18. Moreno LA, Pineda I, Rodríguez G, Fleta J, Sarría A, Bueno $M$. Waist circumference for the screening of the metabolic syndrome in children. Acta Paediatr. 2002; 91: 1307-12.

19. Murphy MJ, Metcalf BS, Jeffery AN, Voss LD, Wilkin TJ. Does lean rather than fat mass provide the link between birth weight, BMI, and metabolic risk? EarlyBird 23. Pediatric Diabetes. 2006; 7: $211-4$.

20. Onis M de, Onyango AW, Van den Broeck J, Chumlea WC, Martorell R. Measurement and standardization protocols for anthropometry used in the construction of a new international growth reference. Food Nutr Bull 2004; 25: S27-36.

21. Onis $M$ de, Lobstein T. Defining obesity risk status in the general childhood population: which cut-offs should we use? Int J Pediatr Obes. 2010; 5: 458-60. Epub 2010 Mar 17.

22. Phillips DIW. Relation of fetal growth to adult muscle mass and glucose tolerance. Diabet Med 1995; 12: 686-90.

23. Ralt D. The muscle - fat duel or why obese children are taller? BMC Pediatr. 2006; 13: 33.

24. Savva SC, Tornaritis M, Savva ME, Kourides Y, Panagi A, Silikiotou N, Georgiou C, Kafatos A. Waist circumference and waist-toheight ratio are better predictors of cardiovascular disease risk factors in children than body mass índex. Int J Obes Relat Metab Disord. 2000; 24: 1453-8.
25. Singhal A, Wells J, Cole TJ, Fewtrell M, Lucas A: Programming of lean body mass: a link between birth weight, obesity, and cardiovascular disease? Am J Clin Nutr. 2003; 77: 726-30.

26. Taylor RW, Williams SM, Grant AM, Taylor BJ, Goulding A. Predictive ability of waist-to-height in relation to adiposity in children is not improved with age and sex-specific values. Obesity (Silver Spring). 2011; 19: 1062-8. Epub 2010 Sep 30.

27. Wajchenberg BL. Subcutaneous and visceral adipose tissue: their relation to the metabolic syndrome. Endocr Rev. 2000; 21: 697-738.

28. World Health Organization. Physical status: the use and interpretation of anthropometry. Geneva: WHO; 1995.

29. World Health Organization. Obesity: preventing and managing the global epidemic. Geneva; 2000 (WHO - Technical Report Series, 894).

30. World Health Organization. Child growth standards based on length/height, weight and age. Acta Paediatr. 2006; 450: S7685.

31. World Health Organization. Development of a WHO growth reference for school-aged children and adolescents. Bull World Health Organ. 2007; 85: 660-7.

32. Ylihärsilä H, Kajantie E, Osmond C, Forsén T, Barker DJP, Eriksson JG: Birth size, adult body composition and muscle strength in later life. Int J Obes (Lond) 2007; 31: 1392-9. Epub 2007 Mar 13.

33. Monteiro CBM, Almeida Junior AD, Wajnzstejn R. Project Management in Health and Medical Research. Journal of Human Growth and Development. 2014; 24(3): 239-242. DOI: dx.doi.org/10.7322/jhdg.88895

34. Atrash HK, Carpentier R. The evolving role of public health in the delivery of health care. Journal of Human Growth and Development. 2012; 22(3): 396-9.

\section{Publish in International Archives of Medicine}

International Archives of Medicine is an open access journal publishing articles encompassing all aspects of medical science and clinical practice. IAM is considered a megajournal with independent sections on all areas of medicine. IAM is a really international journal with authors and board members from all around the world. The journal is widely indexed and classified Q1 in category Medicine. 